\title{
Soliloquy - Subjective Intent Expression in Painting
}

\author{
Jinhua Cheng
}

Sichuan Preschool Education College, Jiangyou, 621709, China

\author{
Keywords: Painting, Soliloquy, Imagination
}

\begin{abstract}
People often soliloquize unconsciously, while such unconscious speech reflects people's inner word truly and also the dialogue between oneself and his soul - self-ask, self-answer, self-affirm, self-suspect, self-console and self-inspect before communication with the outer world. It is required to fully focus on and apply such unconscious soliloquy. Soliloquy has diverse manifestation modes. Painting is a visual expression mode of soliloquy. Painting imagination is bred in soliloquy, and painting result is reflected in soliloquy. Under conscious and unconscious functions, imagination becomes visual from abstract through material form to complete creation process.
\end{abstract}

\section{Introduction}

Under various understandings of art, current art forms are diversified. Flourishing artistic works reflect different aesthetical standards, aesthetic judgments and creation abilities of artists. It seems that there are no uniform standards for artistic works, but there is a rule. The essence of art lies in its uncertainty and many contingencies attached to artists' subjective spirit.

Under such numerous situation, how should we appreciate, understand, create, be loyal to understanding of art and establish our own aesthetic system? This deserves thinking. In my view, the essence of art tends to showing and exchanging emotion. This involves subjective and private parts. Only real works have vitality. Soliloquy in self-thought and self-review is presented in painting form.

\section{Manifestation modes of art}

Art owns multiple manifestation modes, such as sculpture, poetry, film \& TV, music, dance, painting, device and even scheme. All these reflect creators' creation intention. The information we receive from these artistic works are revealed unwittingly or stressed deliberately by creators. Creators choose expression modes according to their habits or theoretical foundation. Art is like a memory system. Artists have respective input and output tools.

In Yi Bing’s poem, "I walk into the dead end along the fingerprint at night/there is no magnificent character/ enter your dream” [1]. We can feel gingerliness for love in the poem. Zuo Zuoxiao Zuzhou hums, "If you will marry / don't marry me/ because like me/ you ask too much/ unless what you gain is lost / like poor stone/ like poor stone..." This reflects helplessness for the reality [2]. The works of Henri Theodore Rousseau (1844 1910) shows original and pure beauty for love of nature and innocence (Fig.1). Marc Chagall (1887-1985) said, "In my inner world, all are realistic and may be more realistic than what we see”; Vincent Willem Van- Gogh (1853-1890) applied jumpy lines and blazing colors to review himself in his self-portrait. Sculpture works of Giacometti Alberto (1901 1966) applied matchstick-type character shape which is fine like bean sprout to symbolize people scorched by flames of war and seized the fleet illusion felt in outer world to disclose the evil of wars. The film of Jia Zhangke Pickpocket tirelessly adjusted exquisite feeling, open fluent, indifferent and straightforward.

These artists expressed their realest emotions with their art experience and life experience in their respective art fields. These real emotions are their essence. They applied works to express themselves. Such self-expression is artists' soliloquy. In the face of these works, we must try to understand their languages in order to feel inner spirit hidden in the language. 

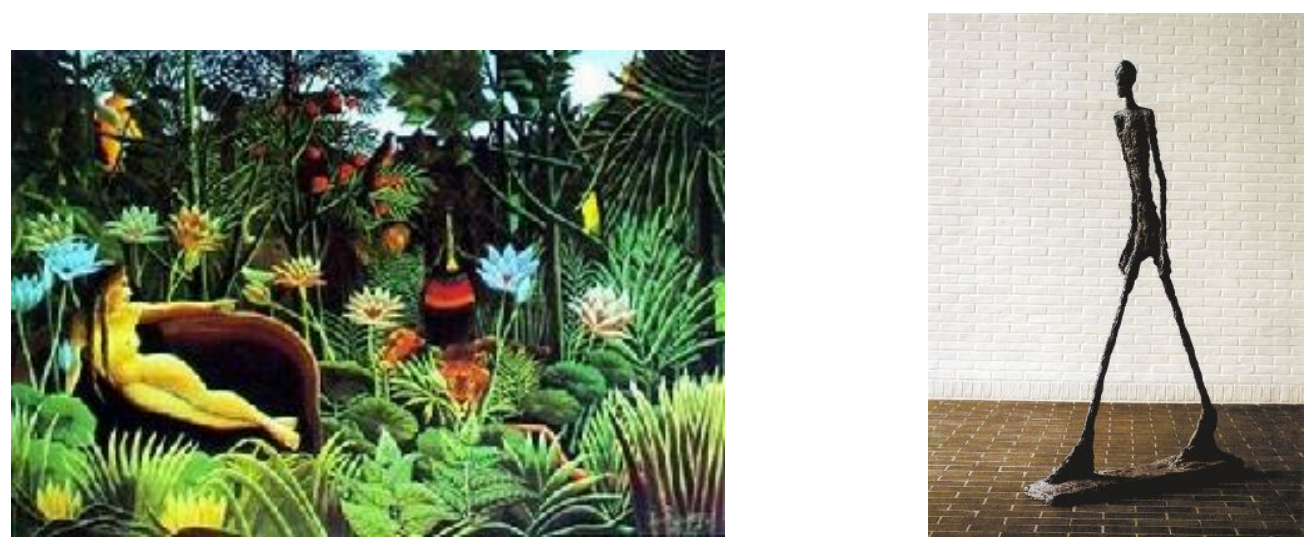

Fig.1. [French] Henri Theodore Rousseau Dream Fig.2. [Swish] Giacometti Alberto Walking Man
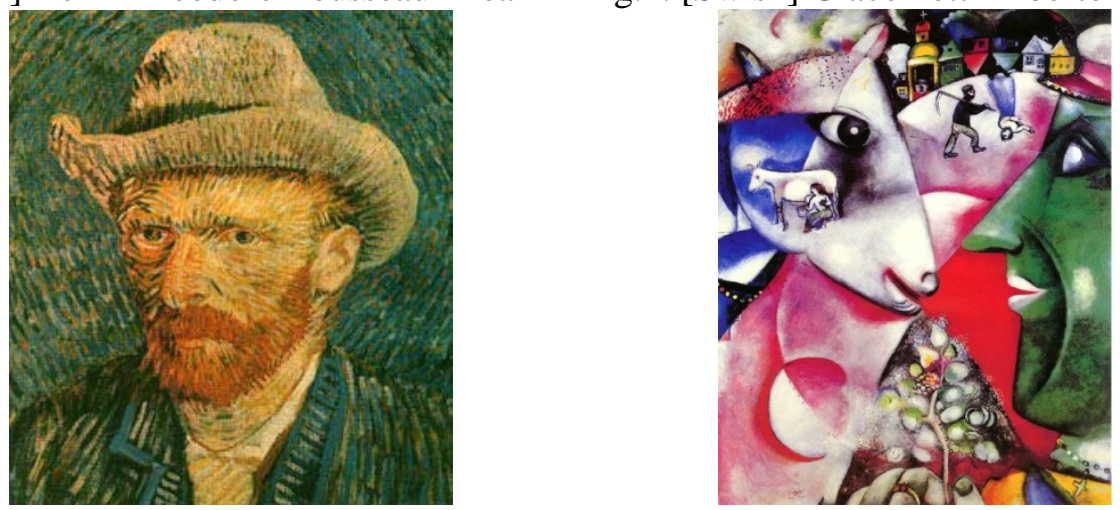

Fig.3. [Dutch] Vincent Willem van- Gogh Self-portrait Fig.4. [Russian] Marc Chagall I and My Village

\section{What's soliloquy?}

Literally, soliloquy means one speaks to himself. Here, soliloquy is not limited to dialogues with oneself by vocal organ. Except voice, our gesture, expression in the eyes and even an action are self-exchange forms which can convey information.

People often unconsciously soliloquize. Such unconscious speech is real response of one's heart. In my opinion, soliloquy is not deliberate expression at all, but uncertain imagination and revealing. Imagination is abstract, outmatches objective reality and is ideal presentation.

\section{Soliloquy by painting}

Soliloquy reveals real inner word unintentionally. In numerous expression approaches, painting is the most visual art form. Painting may depict nature or express creators' subjective feelings. If the paintings can better move audiences, they are more vigorous. The creation ways of latter cannot be separated from imagination. Imagination is not to repeat old experience, but new things penetrate in it for recombination. Creators gradually rise to consciousness level from subconscious, first awake and experience. Then, their creation desire is aroused. They express their emotions through paintings in imagination and finish creation.

\section{Imagination in painting}

Imagination is envisioning [3]. Imagination uncertainty and self-affirmation have strong subjectivity. Of course, such subjectivity is based on real cognitive system. Creators are loyal to their desires and the general imagination according to their previous experience. In painting creation, imagination is accompanied with association, and irrelevant things are associated to reflect a feature in the works. Such association is presupposed and guided by positive or negative emotions. At this moment, creators play the role of a bystander to observe, record, refine and express all these.

Imagination owns authenticity. Here, authenticity is not accessible objective fact, but real mental feeling and emotional experience. It cannot be touched, but can only be felt. Such reality is abstract. We need to pry into and discover it with the help of some traces. Take Edvard Munch for example. 
His painting works contain strong subjectivity, sadness and depression. He tried to show illness, death, despair, love, pain, respiration and sorrow with lines and strong colors. Munch wanted to depict the body full of symbolic meaning. To reach this purpose, he racked his brains to conceive and create tense atmosphere to the works.

\section{Painting imagination is bred in soliloquy}

"Art creation is just an imagination before it is not conveyed." [4] Such imagination gradually forms in soliloquy. This may be unconsciousness in subconscious. Once the subject awakens and enters pre-consciousness, the subject will extract, recall unconscious imagination and enter consciousness level to think how to record and express it. Here, imagination completed the metamorphosis from unconsciousness to consciousness.

Soliloquy is a cradle to breed imagination, while real feeling in imagination is the soul of creation. In soliloquy, imagination is like a germ cell which divides quickly, continuously swells, perfects nervous system and digestive system, gradually gowns into a fetus with consciousness and emotion and waits for delivery. Imagination bred in soliloquy is the motive power of creation. The works is just the result.

Yoshitomo Nara said in his documentary that, "the sense of loneliness and alienation is my driving force of creation". We can see indifference, small evil, loneliness, stubbornness, willfulness and desire from the faces of figures in his works. The spirit presented in the works is related to creator's character and experience.

\section{Painting result is presented in soliloquy}

Imagination will finally become visual from abstract through material form. This process is creation. We present imagination for audiences through painting, then exchange and resonate.

It is not easy to show soliloquy through paintings. Of course, we may be unable to fully express what we think. Some things can only be felt, but cannot be expressed in words. On the contrary, there will be unexpected harvest in the expression process. Frangcis Bacon said, "I'm conceiving, but I can never reach the expected result, and they change." [5] We always present the thought we want to convey through images, make imagination materialized visually through an objective means. If there is no such process, there is no emotional transmission channel with audiences. Painting lets us soliloquy have audiences.

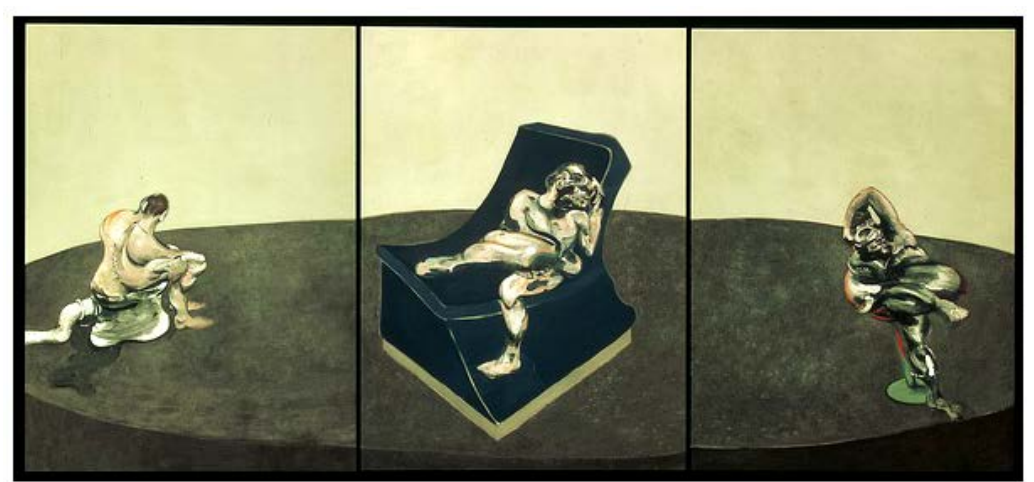

Fig.5. [British] Works of Frangcis Bacon

Imagination is private and sole. We impossibly present it for the public fully. Some things are always retained. The part presented will not be identical, because there is individual difference. Owning individual art language and style is a mark for a creator to be mature. Soliloquy makes creators' works affix to unique independent marks. With self-judgment ability, creators can present their status, express their emotions and achieve their purpose with their own language so as to make the works own obvious individual features. Repeating and imitating others is equal to losing oneself. If art loses independence and individuality, it will nit own vitality. Each creator should make sure his individuality and art are not swallowed by external tide.

With a general survey of art history, some artists influence the public; some artists influence other artists; some artists become other artists. It is vey clear that creators should follow the development direction. 


\section{References}

[1] Qiao Yibing, Collection of poems of Yi Bing. Beijing: Writers Publishing House, 2005

[2] Zuxiao Zuzhou, When I leaves you. Zuxiao Zuzhou Studio, 2005.

[3] Xu Shaofeng, Modern Chinese Dictionary. Beijing: Zhonghua Book Company, 2008: P2232

[4] Zhu Guangqian, Psychology of Literature and Art. Shanghai: Fudan University Press, 2010: P178

[5] Francis Bacon, Maxim, Contemporary Artist Dictionary, Jilin Fine Arts Press, 2006, p23. 